\title{
TEC anomalies-Local TEC changes prior to earthquakes or TEC response to solar and geomagnetic activity changes?
}

\author{
Edward L. Afraimovich ${ }^{1}$ and Elvira I. Astafyeva ${ }^{1,2}$ \\ ${ }^{1}$ Institute of Solar-Terrestrial Physics SB RAS, PO Box 291, 664033, Irkutsk, Russian Federation \\ ${ }^{2}$ Dept. of Natural History Sciences, Hokkaido University, Kita-ku, N10 W8, Sapporo 060-0810, Japan
}

(Received January 7, 2008; Revised June 10, 2008; Accepted June 25, 2008; Online published October 15, 2008)

\begin{abstract}
A number of papers have reported on deviations of daily values of the maximum electron concentration of the ionospheric $F_{2}$ layer and/or total electron content (TEC) in the vicinity of an earthquake's epicenter some time prior to the quake. Owing to the importance of this problem, a question of a "locality" of those effects is emerging. To study this issue we have developed a method based on the calculation of global electron content and of local electron content in "check-region" with low seismic activity. The effect of TEC day-to-day changes before strong earthquakes is analyzed in this work. It is shown that in some cases this effect might be a reflection of global changes of the ionization caused by the 27-day variations as well as other fast alterations due to solar and geomagnetic activity changes. We discuss the problem of certain data corrections that permit local changes to be distinguished from global ones.
\end{abstract}

Key words: Ionosphere, total electron content, global electron content, seismo-ionospheric phenomena, earthquakes precursors, solar activity.

\section{Introduction}

The ionospheric effects produced by seismic activity have attracted geophysicists' attention for many years due to the acute need for the timely prediction of large earthquakes that cause massive destruction and many hundreds of human deaths annually. In this respect, the study of the ionosphere state prior to the occurrence of large earthquakes is one of the most important tasks of modern geophysics and radio physics.

Many papers have been devoted to the validation of different ionospheric methods of earthquake's forecasts (e.g., reviewed by Pulinets et al., 2003; Pulinets and Boyarchuk, 2004; Rishbeth, 2006a, b; Dautermann et al., 2007). A number of papers have reported on deviations in the daily values of the maximum electron concentration of the ionospheric $F_{2}$ layer and/or total electron content (TEC) in the vicinity of an earthquake's epicenter within some days prior to the main shock (Pulinets, 1998; Pulinets et al., 2003; $\mathrm{Pu-}$ linets and Boyarchuk, 2004; Liu et al., 2001, 2004, 2006; Zakharenkova et al., 2007).

Liu et al. (2006) investigated the relationship between variations in the plasma frequency at the ionospheric $F_{2}$ peak $f_{0} F_{2}$ and 184 earthquakes with magnitude $M>5.0$ during 1994-1999 in the Taiwan area. The pre-earthquake ionospheric anomalies, defined as an abnormal decrease more than about $25 \%$ of the ionospheric $f_{0} F_{2}$ during the afternoon period, 1200-1800 LT, significantly occurred within 5 days before the earthquakes. According to the review of Pulinets et al. (2003), the main properties of TEC

Copyright (c) The Society of Geomagnetism and Earth, Planetary and Space Sciences (SGEPSS); The Seismological Society of Japan; The Volcanological Society of Japan; The Geodetic Society of Japan; The Japanese Society for Planetary Sciences; TERRAPUB variations associated with earthquakes precursors, are:

(1) seismically induced precursors affect the plasma density (relative to a normal non-perturbed state) and can be observed between 5 days to a few hours prior to the earthquake;

(2) pre-seismic variations are comparatively short in time (about 4-6 h) relative to magnetic storm effects;

(3) TEC anomalies associated with earthquake's preparation can have a positive or negative sign;

(4) seismically induced variations have the same amplitude as the day-to-day variability of the ionosphere $( \pm 30 \%)$, but they can be much more pronounced, up to $100 \%$, at specific moments of local time;

(5) the sign and shape of seismo-ionospheric variations are known to depend on local time though this dependence may be different for different latitudes and longitudes and will require additional research for every geophysical location;

(6) seismogenic effects on the ionosphere are determined by the size of the earthquake preparation zone and by the threshold of the magnitude of 5;

(7) the affected area of the ionosphere at the height of the $F$-layer maximum reaches $\sim 40^{\circ}$ both in latitude and longitude; the TEC seismo-ionospheric variations agree well with the measured deviations in the critical frequency.

This approach continues to be developed. Pulinets et al. (2007) studied correlations between the records of GPS receivers in different areas and discovered that in a majority of cases the correlation coefficient grows during geomagnetic disturbances. However, before earthquakes, the correlation coefficient drops to within about a 700-kilometer 
diameter around the earthquake epicenter. This allowed $\mathrm{Pu}-$ linets (2007) to formulate a special index of the ionosphere variability, which is sensitive to the pre-earthquake variations and much less sensitive to the magnetic storm variations. In particular, Pulinets et al. (2007) showed that a few days before the California's 16 October 1999 Hector Mine earthquake $(M=7.1)$ the variability index was higher than during a strong $\left(D_{\text {st }} \sim-250 \mathrm{nT}\right)$ geomagnetic storm. At the same time, by the example of the same California's 16 October 1999 Hector Mine earthquake, Afraimovich et al. (2004) showed that the observed TEC variations seem to have been controlled by the local time and by fairly moderate geomagnetic activity instead of being associated with any expected processes that usually accompany earthquake preparation.

Dautermann et al. (2007) have investigated ionosphere electron content variations preceding the San Simeon (22 December 2003, $M=6.6$ ) and Parkfield (29 September $2004, M=6.0$ ) earthquakes in Southern California, using GPS TEC measurements performed by a dense network of 256 continuous GPS stations centered in the Los Angeles basin (SCIG Network). TEC time series averaged over the entire network have been found to be dominated by diurnal $(24 \mathrm{~h})$ and semidiurnal $(12 \mathrm{~h})$ periods reflecting daily solar activity and lunar tides. It has been also found that the period surrounding the San Simeon earthquake suffered from significant space weather effects, so that the precursory event reported by Pulinets et al. (2004) was most likely an artifact resulting from that enhanced space weather activity.

The most significant and substantial doubts concerning the "anomalies" of TEC behavior considered in many papers as earthquake's precursors were stated by Rishbeth (2006a, b). Thus, on the one hand, it is necessary to obtain stronger evidence for the statistical significance of the observed precursors, taking into account the real accuracy of the vertical TEC estimations (no more than 20-30\%; Mannucci et al., 1998); besides, an analysis of such anomalies that are not related to the earthquake's preparation processes is important. On the other hand, any methods used for such purposes, must be based on reliable physical mechanisms. In this work we propose a method that allows us to test whether TEC daily variations preceding earthquakes are of local character; this method takes into account the possible influence of 27-day variations of the ionosphere, caused by the rotation of the Sun and other global TEC variations.

Thus, the main purpose of this study is to compare local TEC changes over an area of an earthquake's epicenter with global TEC variations and with local TEC over a seismically quiet "check"-region (located from the epicenter farther than the earthquake's preparation radius). We also adduce comparison with variations of the index of geomagnetic activity, $K_{\mathrm{p}}$.

\section{Estimation of Global and Regional TEC}

It is known that solar and geomagnetic activity variations cause not only global changes, but also well-pronounced local perturbations of the ionosphere parameters that can mask processes of earthquake preparation (Afraimovich et al., 2004; Rishbeth, 2006a; Dautermann et al., 2007).
Therefore, our chance of revealing ionosphere precursors of earthquakes is very slight under moderate and, especially, under high geomagnetic activity.

Therefore, it is very important to take into account variations of solar activity that are purely global in character. For this purpose, we calculate global electron content (GEC) that is equal to the total number of electrons in the near-Earth space environment within the GPS orbital altitude of about 20,200 km (Afraimovich et al., 2006, 2008; Astafyeva et al., 2007). Therefore, such an approach allows us to track the dynamics of global ionosphere.

In this study we use the GEC conception in order to check the "locality" of TEC anomalies that have appeared some time before earthquakes. We estimated the mean TEC value over an examined area, i.e., the mean total electron content $\langle I(t)\rangle$. The value of $\langle I(t)\rangle$ for the whole globe is proportional to the value of GEC.

GEC can be calculated from global ionosphere maps (GIM) that are available from ftp://cddisa.gsfc.nasa.gov/pub/gps/products/ionex/. GIM contain data of the vertical TEC with spatial steps $5^{\circ}$ of longitude and $2.5^{\circ}$ of latitude - the elementary GIM cell-and temporal step of $2 \mathrm{~h}$. The total number of cells equals 5,184 (72 cells of longitude multiplied by 72 cells of latitude). Then, mean total electron content $\langle I(t)\rangle$ was calculated by summing the absolute vertical TEC values $I_{i, j}$ for every GIM cell (Afraimovich et al., 2006):

$$
\langle I\rangle=\frac{\sum I_{i, j}}{N}
$$

where $i, j$ are the numbers of GIM cell; $i=1,2, N$.

It should be noted that the accuracy of the estimation of the global mean TEC $\langle I(t)\rangle$ is higher than 0.5 TECU (Astafyeva et al., 2007), whereas that of the local mean TEC is less than 5 TECU. The estimations of TEC in each GIM cell are independent so, the relative error of GEC estimation is defined as

$$
\eta=\frac{\sigma_{\mathrm{GEC}}}{m_{\mathrm{GEC}}}=\frac{\sqrt{\sum S_{i, j}^{2} \sigma_{i, j}^{2}}}{\sum S_{i, j} I_{i, j}}
$$

where $\sigma_{\mathrm{GEC}}, m_{\mathrm{GEC}}, \sigma_{i, j}$ are GEC RMS, mean GEC, TEC RMS in GIM cell $(i, j)$, respectively. If $S_{i, j}=S, \sigma_{i, j}^{2}=\sigma^{2}$, $I_{i, j}=I$ then relative error will be equal to $\eta=\frac{\sigma}{I \sqrt{n}}$, where $n=5,184$, the number of GIM cells.

The main idea of the proposed study is the following. Monotonous increase (or decrease) of the maximum TEC within some days might not be associated with local TEC changes, but with an increase (or decrease) of the global electron content caused by the certain alterations in the Solar UV radiation flux. Afraimovich et al. (2008) have found a strong resemblance of the GEC and UV radiation and solar radio emission at $10.7-\mathrm{cm}$ wavelength changes during the 23rd cycle of solar activity. The spectrum of the GEC variations is very wide and includes components with various time periods. GEC is characterized by strong seasonal (semi-annual) variations, with a maximum relative amplitude of about $10 \%$ during the rising and falling parts of the solar activity and up to $30 \%$ during the period of maximum. However, the period of such variations is much longer than 
the duration of observed "anomalies", so they can be not taken into account. This is even more important in terms of GEC variations due to solar cycle activity changes.

At the same time, the maximal deviations in the relative amplitude of 27-day GEC variations can exceed 20-30\% (Astafyeva et al., 2007; Afraimovich et al., 2008). For the absolute TEC values of 20 TECU, this amounts to TEC changes within 10 TECU (or more) that is of a comparable amplitude with TEC “anomalies" reported before $(\mathrm{Pu}-$ linets, 1998; Liu et al., 2001, 2004; Pulinets et al., 2003; Pulinets and Boyarchuk, 2004; Zakharenkova et al., 2007). Besides, the duration of the phase of 27-day GEC variations with maximum derivative value is of the same order (about 7 days) as the duration of TEC anomalies recorded in the papers mentioned above.

It should be noted that GEC changes can be caused not only by 27-day variations but also by the dynamics of the UV radiation from different active regions of the Sun. The contribution of such regions to the total UV flux may be of the same order as changes due to the solar rotation. This became especially apparent during the period of high solar activity in the autumn-winter of 2003 and in the autumn of 2004 (Afraimovich et al., 2008).

In addition, we test the "locality" of TEC anomalies. For this purpose, we compare local TEC in the area of a future epicenter with simultaneous TEC changes within a "check-region" with low seismic activity. In the case where a TEC "anomaly" is caused by global variations of ionization, analogous anomalies should also be observed in seismically-quiet regions. In this work we estimate mean TEC value for the territories $52-55^{\circ} \mathrm{N} ; 35-$ $40^{\circ} \mathrm{E}$ (Moscow area), $52-55^{\circ} \mathrm{N} ; 90-105^{\circ} \mathrm{E}$ (Irkutsk area), $62-65^{\circ} \mathrm{N}, 125-130^{\circ} \mathrm{E}$ (Yakutsk area), $50-60^{\circ} \mathrm{N} ; 90-105^{\circ} \mathrm{W}$ (North Canada). We have chosen several seismically-quiet "check-regions" with geophysical conditions similar to the ones of the study areas (geomagnetic latitude, longitudinal range etc.).

\section{Observations}

Firstly, we examine local dependence of the averaged TEC before the earthquake on 21 September 1999 in the vicinity of Taiwan with magnitude $M=7.3$ (the Chi-Chi earthquake). Local TEC values $\langle I(t)\rangle$ were estimated by averaging values over the territory $20-26^{\circ} \mathrm{N} ; 118-124^{\circ} \mathrm{E}$ within 10 days before and 9 days after the earthquake (Fig. 1(b) and 1(c), black curves).

Figure 1(a) shows global TEC variations for the entire 1999; Fig. 1(b) shows global (thick gray curves, right scale) and regional (black curves, left scale) TEC for the examined 20 days (254-274 days, indicated by thin vertical lines on panel (a)). The arrow in Fig. 1(b) indicates an anomalous (compared to other days) sudden decrease of the maximum TEC level 4 days before the earthquake. A similar effect of TEC and $N_{\mathrm{m}} F_{2}$ deviations was considered by Liu et al. (2004) to be a pre-earthquake ionosphere anomaly that appeared on 17-18 of September. However, it is obvious that such a significant decrease is also pronounced in the global TEC dependence (Fig. 1(b), gray curve) on the background of monotonous increase of global ionization at the rising phase of 27-day variations. Besides, comparison data for

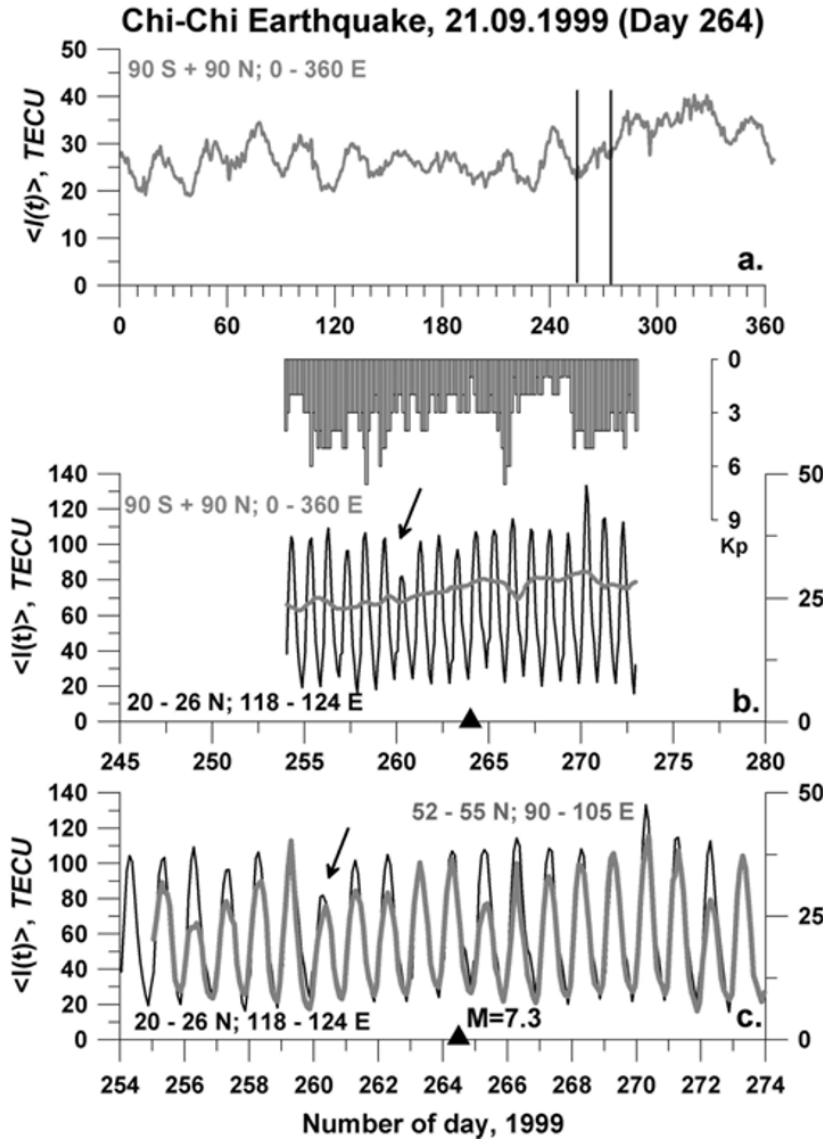

Fig. 1. Global and local TEC variations before and after the Chi-Chi earthquake on 21 September 1999. Upper bar chart on panel (b) shows variations in the index geomagnetic activity, $K_{\mathrm{p}}$, within the examined time period. For TEC series estimated above the "check-region", the time-scale is shifted in time taking into account the difference in local time.

the "check-region" Irkutsk (after $1 \mathrm{~h}$ ) show the same trend of TEC changes. It should be noted that this same sudden decrease of TEC coincides with a diminution of the index of geomagnetic activity $K_{\mathrm{p}}$ (panel (b)). Thus, the observed anomalous decrease represents changes in the global TEC and might not be related to earthquake's preparation.

Secondly, we analyze the local dependence of the mean TEC level around the area of the earthquake on 25 September 2003 (the Tokachi-oki earthquake) in the vicinity of Hokkaido Island, Japan, with the magnitude $M=8.3$ (the time of the quake is indicated by black triangles in Fig. 2(b, c)). Figure 2(a) shows variations in the global TEC during the whole year 2003. The analyzed time period of 10 days before and 10 days after the earthquake (258-278 days of 2003 ) is indicated by vertical thin lines and appears to be a part of rising phase and the maximum of 27-day variations.

Local TEC values $\langle I(t)\rangle$ were estimated by averaging over the territory $32-38^{\circ} \mathrm{N} ; 130-140^{\circ} \mathrm{E}$ and are shown in Fig. 2(b) and 2(c) (black curves). Arrows on panels (b) and (c) show "anomalous" (against previous days) increasing of TEC maximum level 2-3 days prior to the earthquake. This effect was reported by Zakharenkova et al. (2007) as a possible precursor of the earthquake. Zakharenkova et al. (2007) also noted a big spatial scale of the observed 


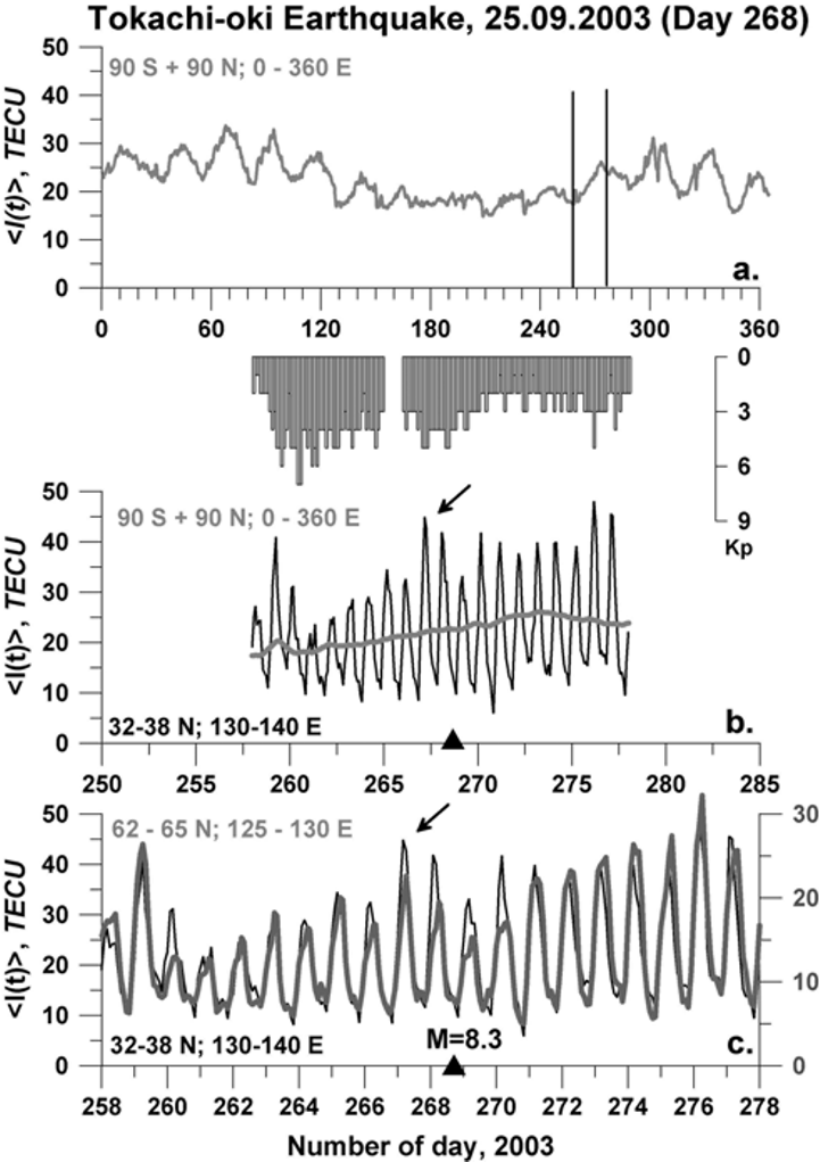

Fig. 2. The same as for Fig. 1 but for the Tokachi-oki earthquake on 25 September 2003.

anomaly (about $2000 \mathrm{~km}$ ).

Apparently, there is no sharp peak in the global TEC that could cause a specific increase of the local TEC (Fig. 2). However, a comparison with TEC changes in the "checkregion" Yakutsk (Fig. 2(c), gray curve) showed that analogous variations appeared there $1 \mathrm{~h}$ later. This fact causes us to doubt the locality of the observed anomalous TEC changes as well as the relation of this anomaly with earthquake preparation. This conclusion becomes even stronger after we find similar way of changes in $K_{\mathrm{p}}$ index variations (Fig. 2(b), bar chart from above).

As the third example, we perform the analysis for the San Simeon earthquake with a magnitude $M=6.6$ that occurred on 22 December 2003 in California, USA. Following the paper by Dautermann et al. (2007), we estimated local TEC within the territory $\left(32-37^{\circ} \mathrm{N} ; 114-123^{\circ} \mathrm{W}\right)$ for the time period from 345 to 365 day of the year 2003 .

One can observe significant increase in the maximal regional TEC value $\langle I(t)\rangle$ that appears 2 days before the San Simeon earthquake (indicated by arrows in Fig. 3(b, c)). Such an effect is clearly part of the global TEC changes (Fig. 3(a) and 3(b)), though, and it lasts for 4 days. Besides, similar TEC variations were observed above the "checkregion" Moscow (Fig. 3(c), gray curve) but $10.5 \mathrm{~h}$ before. For TEC variations above the "check-region" in Fig. 3(c) the time scale is shifted for the difference in local time of $10.5 \mathrm{~h}$. Apparently, the sudden TEC increase occurred due
San Simeon Earthquake, 22.12.2003 (Day 356)
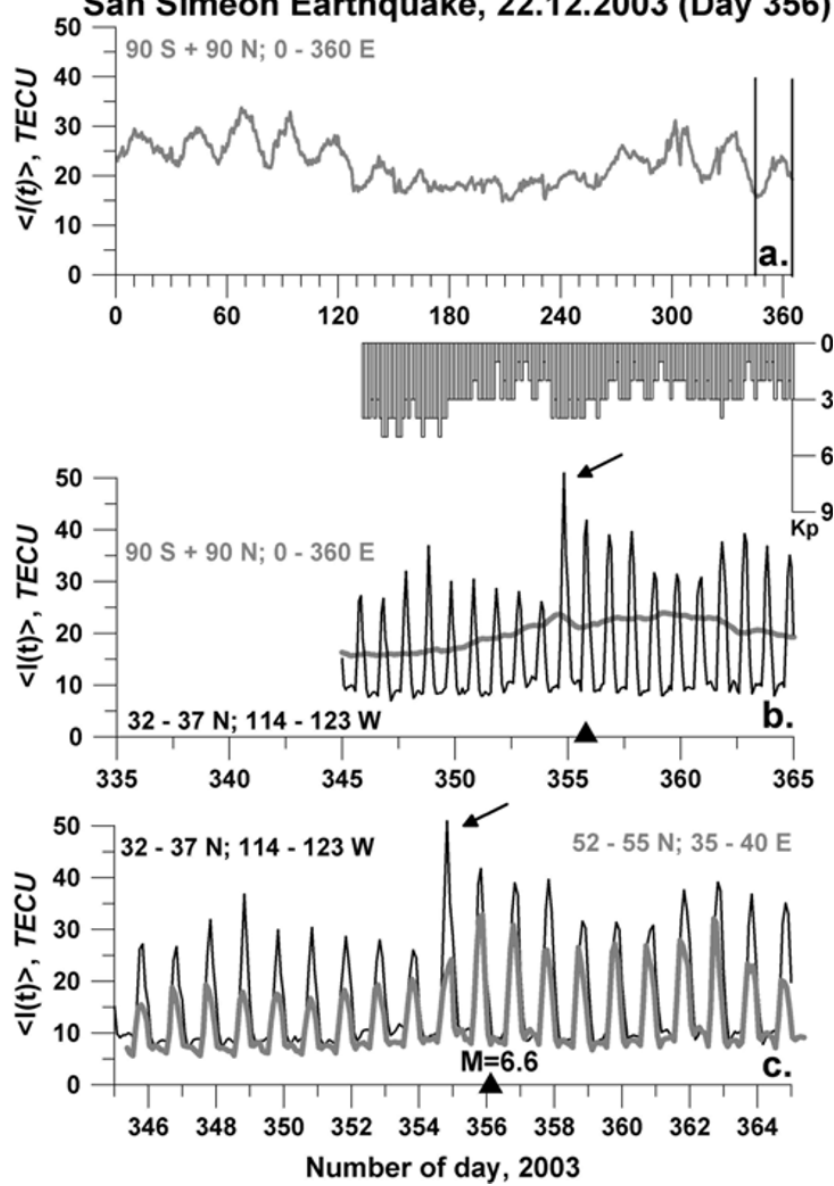

Fig. 3. The same as for Fig. 1 but for the San Simeon earthquake on 22 December 2003.

to enhanced solar activity and hardly has anything to do with pre-earthquake phenomena.

As the fourth example, let us make calculations for the $M=6.0$ Parkfield earthquake that occurred on 29 September 2004 in California, USA (Fig. 4). Local TEC was estimated within the territory $\left(32-37^{\circ} \mathrm{N} ; 114-123^{\circ} \mathrm{W}\right)$ for the time period from 262 to 283 day of the year 2004 (Fig. 4(b, c), black curves).

It is obvious from Fig. 4(b) (black curves) that the maximal TEC value decreases monotonously, since it corresponds to the falling phase and the minimum of 27-day variations (Fig. 4(a)).

The arrow in Fig. 4(b) indicates an "anomalous" increase of the maximum TEC level 5 days before the earthquake that evidently stands out against the background tendency to decrease. Obviously, we do not observe such kind of sudden TEC change in the check-region of North Canada (Fig. 4(c), gray curve), and the value of $K_{\mathrm{p}}$ index of geomagnetic activity does not exceed 2 and characterizes the conditions as quiet ones. Therefore, the observed anomaly seems to have a local character and can be a pre-seismically induced effect.

Next, let us analyze TEC changes before and after the Kuril Island earthquake on 15 November 2006 ( $M=7.9)$. We estimated regional TEC around a large area around the epicenter $\left(35-55^{\circ} \mathrm{N} ; 145-165^{\circ} \mathrm{E}\right)$ for the time period 

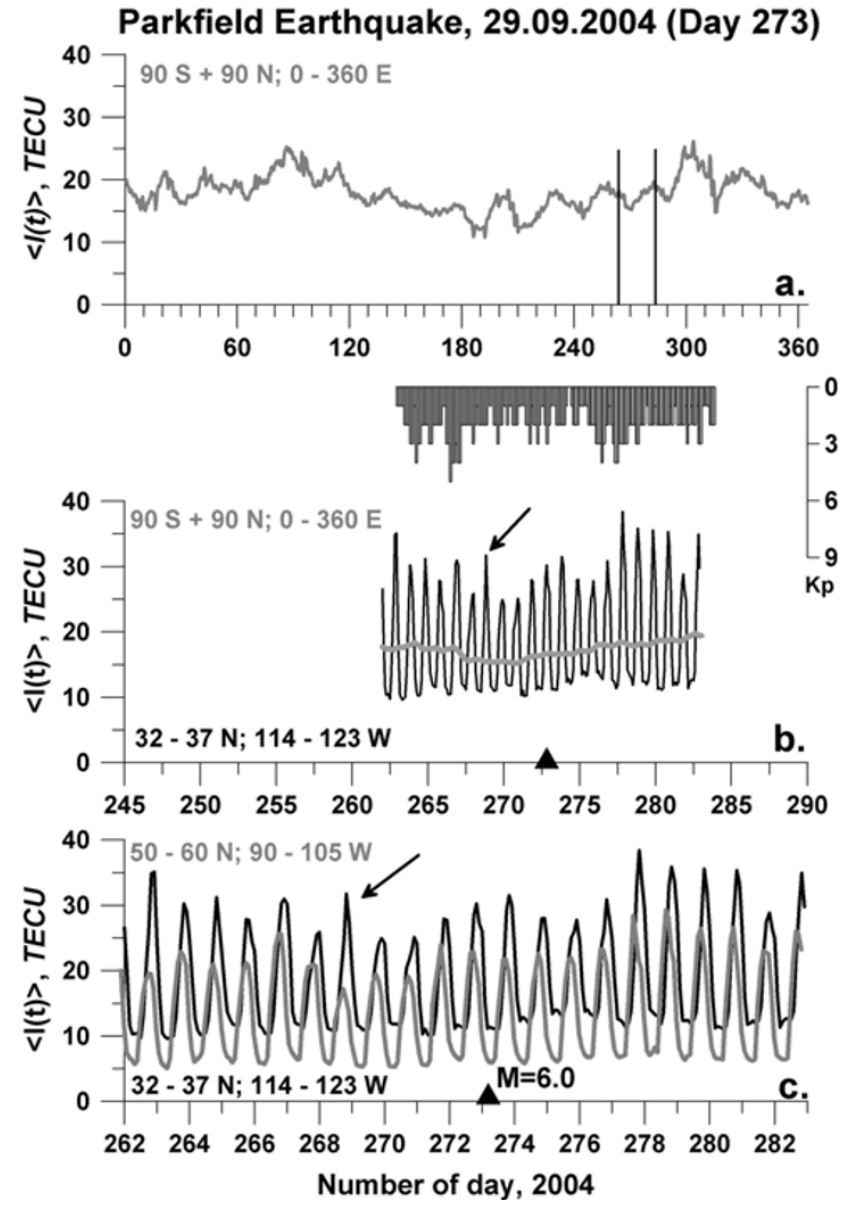

Fig. 4. The same as for Fig. 1 but for the Parkfield earthquake on 29 September 2004.

from 310 to 330 days and compared it with TEC above the Moscow area $\left(52-55^{\circ} \mathrm{N} ; 35-40^{\circ} \mathrm{E}\right)$. The absolute value of the global TEC (Fig. 5(a)) is smaller than that for the other events analyzed here in that it does not exceed 12 TECU; the reason for this lies in the fact that the year 2006 corresponds to the period of low solar activity (close to the minimum of the 23rd solar cycle), therefore, 27-day variations are not so well pronounced as during the rising and falling parts of the solar activity cycle (Astafyeva et al., 2007; Aframovich et al., 2008).

Regional TEC dependence around the earthquake area shows a sudden significant increase 5 days prior to the earthquake (the time of the quake is indicated by black triangle). It is obvious that such an "anomaly" corresponds to the sudden spike in global TEC (Fig. 5(b)). Moreover, from Fig. 5(c) we can see that such a spike is reflected in the TEC value within the check-region as well, even if the absolute value of TEC is smaller due to latitudinal TEC distribution. Therefore, the regional TEC variations have obviously been controlled by the geomagnetic activity changes (according to the data from http://www.ukssdc.ac.uk/wdcc1/wdc_menu.html, the index $K_{\mathrm{p}}$ reached a value of 7 on day 314 , as shown by bar chart from above in Fig. 5(b)), instead of being associated with any expected processes that usually accompany the earthquake preparation.
Kuril Islands Earthquake, 15.11.2006 (Day 319)
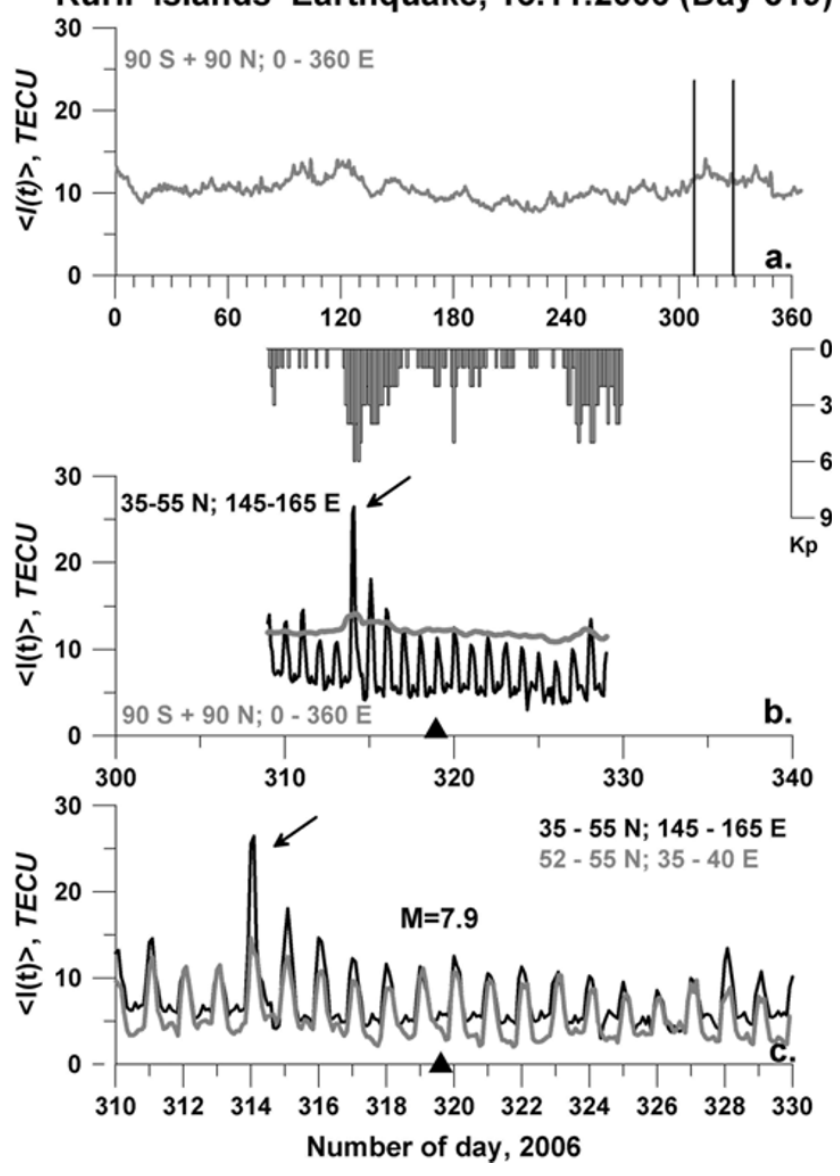

Fig. 5. The same as for Fig. 1 but for the Kuril Islands earthquake on 15 November 2006.

\section{Discussion and Conclusion}

Our comparison of local and global TEC values for the events examined here showed that TEC anomalies observed in the area of a future earthquake could be caused not as much by the enhanced seismic activity before earthquakes as by changes in the global ionization due to dynamics of the UV solar radiation or/and geomagnetic activity. The delay of analogous changes in the "check-region" is caused by the difference in local time and by latitudinal distinctions.

The results of our comparative analysis of global and regional TEC changes before earthquakes conform to the known fact that "the affected area of the ionosphere at the height of the $F$-layer maximum reaches $\sim 40^{\circ}$ both in latitude and longitude" (Pulinets et al., 2003). This fact appears to be additional evidence that the observed anomalies can be consequences of the global changes of the ionization but not processes in the area of earthquake's preparation.

Thus, to establish the fact of earthquake preparation for certain, it is not sufficient to carry out only a statistical analysis of TEC changes within a seismo-active region as has been performed in a majority of studies (Pulinets, 1998; Liu et al., 2001, 2004, 2006; Pulinets et al., 2003, 2004; Pulinets and Boyarchuk, 2004; Pulinets et al., 2007; Zakharenkova et al., 2007). It is also necessary to accomplish a fundamental analysis of the main global factors responsible for the formation and changes of local TEC solar UV ra- 
diation and redistribution of ionization during geomagnetic disturbances.

Dautermann et al. (2007) analyzed variations of $F_{10.7}$ solar flux in order to show that local TEC changes can be caused by large fluctuations in the solar flux. However, the approach proposed here allows use of global TEC and local TEC changes in "check-region" with low seismic activity as a more appropriate indicator of global changes of ionization, which takes into account not only changes of solar radiation but also the dynamics of geomagnetic activity.

In order to separate the relative contribution of processes of "global character" to TEC changes, supplementary investigations are necessary, as well as the development of special methods for realizing such distinctions, based on a model of seismo-ionosphere coupling. This problem is a complex one and is beyond the scope of this study. As a result of such corrections, the seismo-ionosphere effect of earthquake's preparation may become either more pronounced, or impaired. In any case, the reliability of conclusions concerning the connection of observed TEC changes with earthquake preparation processes will improve.

The method proposed here and quantitative estimations are correct for variations in the critical frequencies measured at ionosondes as well. Therefore, further comparison of the data series of critical frequency data or TEC with the dynamics of global electron content would be of interest. In particular, it would be interesting to analyze the certain GEC alterations for earthquakes with magnitude $M>5.0$ during 1994-1999 in the Taiwan area and to compare them with "local" variations of the ionospheric peak of $F_{2}, f_{0} F_{2}$, obtained by Liu et al. (2006).

The approach stated above can be performed not only for studying ionosphere "anomalies" of seismic origin but also for other local events, such as hurricanes, typhoons, weather cyclones and anthropogenic effects.

Acknowledgments. We are grateful to Ilya V. Zhivetiev for his help in programming. We acknowledge the Jet Propulsion Laboratory of California Institute of Technology (JPL) for GIM. The work was supported by the Russian Foundation for Basic Research (RFBR grant No. 07-05-00127 and RFBR-GFEN grant $\mathrm{N}$ 06-05-39026), the SB RAS collaboration project N 3.24 and by the Japanese Society for the Promotion of Science (JSPS). Finally, the authors wish to thank the referees for valuable suggestions which greatly improved the presentation of this paper.

\section{References}

Afraimovich, E. L., E. I. Astafieva, M. B. Gokhberg, V. M. Lapshin, V. E. Permyakova, G. M. Steblov, and S. L. Shalimov, Variations of the total electron content in the ionosphere from GPS data recorded during the Hector Mine earthquake of October 16, 1999, California, Russian J. Earth Sci., 6(5), 339-354, 2004.

Afraimovich, E. L., E. I. Astafyeva, and I. V. Zhivetiev, Solar activity and global electron content, Doklady Earth Sci., 409A(6), 921-924, 2006.

Afraimovich, E. L., E. I. Astafyeva, A. V. Oinats, Yu. V. Yasukevich, and I. V. Zhivetiev, Global Electron Content: a new conception to track solar activity, Ann. Geophys., 26, 335-344, 2008.

Astafyeva, E. I., E. L. Afraimovich, A. V. Oinats, Yu. V. Yasukevich, and I. V. Zhivetiev, Dynamics of global electron content in 1998-2005 derived from global GPS data and IRI modeling, Adv. Space Res., http://dx.doi.org/10.1016/j.asr.2007.11.007, 2007.

Dautermann, T., E. Calais, J. Haase, and J. Garrison, Investigation of ionospheric electron content variations before earthquakes in southern California, 2003-2004, J. Geophys. Res., 112, B02106, doi:10. 1029/2006JB004447, 2007.

Liu, J. Y., Y. I. Chen, Y. J. Chuo, and H. F. Tsai, Variations of ionospheric total electron content during the Chi-Chi earthquake, Geophys. Res. Lett., 28(7), 1383-1386, 2001.

Liu, J. Y., Y. J. Chuo, S. J. Shan, Y. B. Tsai, Y. I. Chen, S. A. Pulinets, and S. B. Yu, Pre-earthquake ionospheric anomalies registered by continuous GPS TEC measurements, Ann. Geophys., 22, 1585-1593, 2004.

Liu, J. Y., Y. I. Chen, Y. J. Chuo, and C. S. Chen, A statistical investigation of preearthquake ionospheric anomaly, J. Geophys. Res., 111, A05304, doi:10.1029/2005JA011333, 2006.

Mannucci, A. J., B. D. Wilson, D. N. Yuan, C. M. Ho, U. J. Lindqwister, and T. F. Runge, A global mapping technique for GPS-derived ionospheric TEC measurements, Radio Sci., 33(3), 565-582, 1998.

Pulinets, S. A., Seismic activity as a source of the ionospheric variability, Adv. Space Res., 22(6), 903-906, 1998.

Pulinets, S. A., Natural Radioactivity, Earthquakes, and the Ionosphere, EOS, 88(20), 217-218, 2007.

Pulinets, S. A. and K. Boyarchuk, Ionospheric Precursors of Earthquakes, 315 pp., Springer, Berlin, Germany, 2004.

Pulinets, S. A., A. D. Legen'ka, T. V. Gaivoronskaya, and V. Kh. Depuev, Main phenomenological features of ionospheric precursors of strong earthquakes, J. Atmos. Sol. Terr. Phys., 65, 1337-1347, 2003.

Pulinets, S. A., T. B. Gaivoronska, and L. Ciraolo, Correlation analysis technique revealing ionospheric precursors of earthquakes, Nat. Hazards, 4, 697-702, 2004.

Pulinets, S. A., A. N. Kotsarenko, L. Ciraolo, and I. A. Pulinets, Special case of ionospheric day-to-day variability associated with earthquake preparation, Adv. Space Res., 39, 970-977, 2007.

Rishbeth, H., F-region links with the lower atmosphere?, J. Atmos. Sol. Terr. Phys., 68, 469-478, 2006a.

Rishbeth, H., Ionoquakes: Earthquake Precursors in the Ionosphere?, EOS, 87(32), 316-317, 2006b.

Zakharenkova, I. E., I. I. Shagimuratov, A. Krankowski, and A. F. Lagovsky, Precursory phenomena observed in the total electron content measurements before great Hokkaido earthquake of September 25, 2003 (M=8.3), Studia Geophys. Geod., 51(2), 267-278, 2007.

E. L. Afraimovich and E. I. Astafyeva (e-mail: elliada@mail.sci. hokudai.ac.jp) 